\title{
(Co)narrações de viagens para Portugal por lusodescendentes no Facebook ${ }^{1}$
}

\author{
Isabelle Simões Marques \\ Universidade Aberta \& CLUNL-FCSH-Universidade Nova de Lisboa \\ Michele Koven \\ University of Illinois at Urbana-Champaign, EUA
}

\begin{abstract}
:
This article combines the study of online narratives as social practices and the linguistic anthropological study of imagined communities, to examine a set of non-canonical narrative practices in a Facebook group for the Portuguese diaspora in France. Instead of reports of individual members' past experiences, these narratives function as invitations to other group members to co-tell typical, shared experiences. Specifically, we investigate how group members share vacation trips to Portugal with each other in ways that produce a sense of collective and simultaneous experience. They accomplish this through deictically-based narrative strategies that shift the social, spatial, and temporal perspectives of narrating and narrated frames in ways that link the following: individual I's with collective we's, one-time events with timeless event types, and co-presence online with co-presence on vacation. Through these strategies, participants connect Facebook narrations of vacations to the larger social project of diasporic longing for and return to Portugal.
\end{abstract}

Keywords: narrative, deictics, Facebook, heritage tourism, roots tourism diaspora, Portuguese descent, France, imagined communities.

Palavras-Chave: narrativa, deíticos, Facebook, turismo de herança, turismo de raízes, diáspora, Lusodescendentes, França, comunidades imaginadas.

\section{Introdução}

Este artigo combina o estudo de narrativas online como práticas sociais com o estudo linguístico antropológico de comunidades imaginadas para examinar um conjunto de práticas narrativas não-canónicas num grupo Facebook destinado à diáspora portuguesa em França.

Discutiremos a forma como os atores sociais usam práticas narrativas digitais, não só para contar as suas experiências individuais, como também para convidar outros participantes a construir e a reconhecer experiências coletivas típicas. Em particular, discutiremos o complexo trabalho social envolvido quando jovens de ascendência portuguesa, a viver em França, partilham as suas viagens de férias a Portugal na rede social Facebook. Especificamente, investigamos como esses posts multimodais contribuem para a compreensão da narrativa como prática social. Examinaremos casos em que as narrativas não são tanto relatos de experiências passadas de membros individuais mas sim convites de projetos sociais coletivos, como o nacionalismo português diaspórico. Notamos, no nosso estudo, que os participantes partilham regularmente um post relacionado com a ida de França para Portugal, acompanhado, muitas vezes, por uma foto da fronteira portuguesa. Os participantes partilham regularmente o tipo de mensagem seguinte:

\footnotetext{
${ }^{1}$ Este artigo é uma adaptação autorizada pela editora John Benjamins de um texto nosso publicado na revista Narrative Inquiry em 2017 e intitulado "We are going to our Portuguese homeland!" French Luso-descendants' diasporic Facebook conarrations of vacation return trips to Portugal. 27(2): 286-310.
} 
(1) "Parce que quand on voit ce panneau, on a les yeux qui petillent on est heureux, joyeux. Et on dit, "Graças a Deus" on est bien arriver!"”

(pt.) "Porque quando vemos este sinal de trânsito, temos os olhos que brilham, estamos felizes, alegres. E dizemos: "Graças a Deus "3 chegámos bem!"4

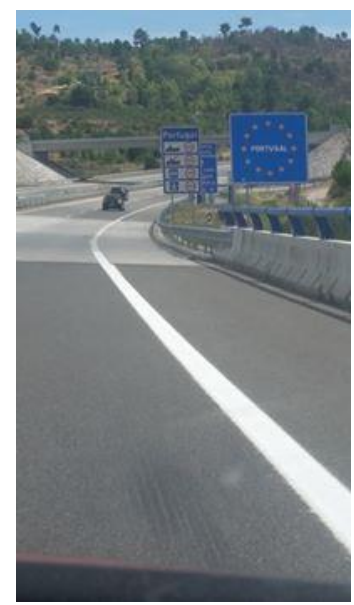

Figura 1

Interessa-nos saber como caracterizar esse tipo de prática comunicativa. Por um lado, estas publicações têm uma qualidade narrativa ao apresentarem uma série de ações que se desenrolam num espaço-tempo distinto do espaço-tempo da interação atual: ao ver os sinais de trânsito, ao atravessar a fronteira e ao citar reações. Por outro lado, estas publicações não correspondem às formas canónicas da narração, descritas por Labov, que privilegiou as narrativas na primeira pessoa do singular sobre eventos passados (Labov, 1972). Em vez disso, estas mensagens são apresentadas num tempo do presente atual ou habitual e segundo uma perspetiva coletiva (on voit/vemos, on est/estamos, on dit/dizemos), onde os termos "a gente/nós/nosso(s)" assinalam os membros do grupo Facebook e, de forma mais geral, os membros da comunidade portuguesa que residem em países francófonos e que desejam reencontrar a pátria da sua família.

O nosso estudo analisa o que este tipo de comunicação online pode revelar sobre práticas narrativas e o que a análise narrativa pode revelar sobre estes tipos de práticas nas redes sociais. Apesar da mudança de tratamento da narrativa como prática social (Ochs \& Capps, 2000; De Fina, 2012; De Fina \& Georgakapoulou, 2015), os estudos narrativos ainda privilegiam frequentemente relatos únicos de locutores sobre as suas experiências individuais. Além disso, os autores na área da sociolinguística que escrevem sobre narrativas têm sublinhado como os atores usam as histórias para efetuar práticas sociais numa escala microanalítica da interação interpessoal (Goodwin, 1990; Mandelbaum, 2013).

$\mathrm{Na}$ medida em que a narrativa permite que os participantes experimentem o mundo da história a partir do "aqui e agora" da interação narrativa, as práticas narrativas envolvem formas de viagem espacio-temporal (Lempert \& Perrino, 2007). Mostraremos como as práticas multimodais semelhantes às narrativas no Facebook permitem formas particulares de viagem espacio-temporal transnacional e simultânea. Ou seja, os participantes usam estratégias narrativas visuais e verbais nas suas interações do Facebook entre si e

\footnotetext{
${ }^{2}$ Reproduzimos a ortografia original dos posts.

${ }^{3} \mathrm{O}$ negrito refere-se à utilização da língua portuguesa no post.

${ }^{4}$ Nossa tradução.
} 
produzem, não só um sentido de partilha de identidade, como também a partilha de um mesmo "nós", assim como a sensação de estarem juntos em dois contextos espacio-temporais de forma simultânea, ou seja, estarem juntos online e offline a caminho de Portugal.

Desta forma, em vez de tratar a narrativa como envolvendo apenas a partilha de experiências previamente vividas pelos indivíduos no passado, examinamos um tipo de prática pouco explorada, em que os membros do grupo verdadeiramente convidam os outros a experimentar uma experiência particular de "ali" e "naquele momento" com os outros no "aqui e agora". Ao fazê-lo, reconhecem que fazem parte de um "nós" coletivo maior. Analisamos como os locutores usam combinações simultâneas de estratégias verbais e visuais multimodais para obter uma forma de mobilização coletiva. Os participantes usam essas estratégias de forma a produzir dois tipos interligados de simultaneidade:

1. A ligação de perspetivas individuais e coletivas: fusão do contexto online de interação no Facebook e o contexto narrado offline da viagem. Os participantes realizam o primeiro tipo de simultaneidade com formas deíticas que vinculam um "eu" individual a um "nós" coletivo e vinculam eventos únicos com tipos de eventos habituais e/ou típicos.

2. Um segundo tipo de simultaneidade: a narração online parece desdobrar-se ao mesmo tempo que a viagem na estrada. Desta forma, os participantes produzem um sentido de "nós" diaspórico fazendo parecer que estão online juntos em França e a caminho de Portugal.

Por meio dessas duas estratégias, os participantes usam a narrativa não apenas na escala interacional da convivência interpessoal mundana, como também numa escala social mais ampla, incorporando formas de nacionalismo português da diáspora, amplamente reconhecidas. Ao partilhar as suas férias, os participantes orientam-se para a ideologia generalizada de retorno (Brettell, 2003), que apresenta Portugal como o lar "real" pelo qual aqueles que estão no estrangeiro devem sempre sentir saudade (Leal, 2000), sentimento considerado emblemático de Portugal e do nacionalismo português diaspórico.

Veremos a seguir que a nossa análise pretende contribuir para duas discussões académicas e estabelecer uma ligação entre elas. Em primeiro lugar, examinamos a maneira como os participantes narram, de forma colaborativa, as suas experiências e identidades coletivas (De Fina, 2012; De Fina \& Georgakapoulou, 2014), sobretudo em contextos digitais (Page, 2012). Em segundo lugar, adotamos uma abordagem oriunda da antropologia linguística norte-americana acerca da noção de comunidades imaginadas (Anderson, 1991; Billig, 1885; Gal \& Woolard, 2001; Silverstein, 2000; Urban, 2000), para considerar como os locutores usam as práticas narrativas para realizar um projeto macrossocial. Iremos rever brevemente estas duas discussões, explicando a nossa contribuição.

\section{Abordagens sociolinguísticas da Narrativa como prática social}

Estudos anteriores da tradição laboviana definem a narrativa como "recapitulando a experiência passada associando uma sequência verbal de cláusulas à sequência de eventos que realmente ocorreram" (Labov, 1972: 359-360, nossa tradução), focalizando a atenção em experiências pontuais, situadas no passado, narradas por narradores individuais, contadas no contexto de entrevistas sociolinguísticas. A abordagem laboviana da narrativa tem sido criticada por prestar uma atenção mínima às interações nas quais as narrativas são contadas e ao trabalho social que essas narrações podem realizar (Polanyi, 1979; Goodwin, 1990; Bamberg, 1997; Ochs \& Capps, 2000; Koven, 2002; Mandelbaum, 2013). De facto, existe atualmente uma robusta tradição que tem examinado as narrativas em termos sociais. Por exemplo, não é necessário presumir que as narrativas são contadas por atores sociais individuais sobre experiências individuais ocorridas num momento anterior à narração. De facto, vários autores examinaram, por exemplo, estruturas participativas não-diádicas, tais como co-narrações multipartidárias (Duranti, 1986; Ochs \& Capps, 2000; Page, 2012), onde vários participantes contam de forma conjunta uma história noutros quadros temporais, como o futuro, o 
presente histórico, o presente habitual, atemporal, ou simultâneo (Goodwin, 1997; Koven, 2016; Ochs, 1994; Ochs \& Capps, 2000; Georgakapoulou, 2007). Essas abordagens mais flexíveis da narrativa, que incluem vários narradores e quadros temporais, têm sido particularmente adequadas para analisar como as pessoas conarram experiências nos media sociais (Georgakapoulou, 2007, 2015) e, mais especificamente, no Facebook (Page, 2012).

No entanto, e apesar dessas abordagens mais flexíveis e alargadas das narrativas, a investigação ainda privilegia histórias de atores sociais numa escala micro-analítica, analisada a uma escala micro-social. Por exemplo, quando autores orientados para o discurso discutem o que os narradores "fazem" uns com os outros, o foco permanece muitas vezes em atividades de escala interpessoal, como as fofocas, as provocações etc. (Goodwin, 1990; Mandelbaum, 2013).

Fazemos assim, neste nosso estudo, duas intervenções no saber da narrativa: primeiro, uma consideração mais aprofundada das formas pelas quais as pessoas podem narrar para além da primeira pessoa do singular relatos de acontecimentos únicos. Neste sentido é necessário considerar sistematicamente como os narradores podem narrar de forma colaborativa não apenas experiências individuais, muitas vezes sinalizadas pela primeira pessoa do singular, como também a forma como os locutores narram experiências e identidades coletivas, muitas vezes sinalizadas pela primeira pessoa do plural (ver Goffman, 1979/1981; BadequanoLópez, 2000; De Fina, 2003; Van De Mieroop, 2014, 2015). Em segundo lugar, demonstramos a importância de uma consideração mais completa de como os locutores usam a narrativa para sinalizar projetos sociais de maior escala, além do nível interpessoal, como o nacionalismo diaspórico.

Começamos com uma definição operacional da narrativa como perspetiva analítica para entender como os atores sociais inter-relacionam os espaços e tempos de dois tipos de eventos ou contextos: os da interação imediata e aqueles que "falam sobre". Assim, se adotarmos essas perspetivas, definimos a narrativa como um discurso que implica uma relação entre um evento narrativo ("narrating event", em inglês), não necessariamente diádico e um evento narrado (ou "narrated event"), não necessariamente passado (Agha, 2005; Bakhtin, 1981; Bauman, 1986; Jakobson, 1957; Koven, 2002, 2004, 2007, 2016; O’Connor, 1994; Perrino 2007; Silverstein, 1993, 2005; Wortham, 2001). Os deíticos, tais como os pronomes e os tempos verbais, são formas discursivas críticas para os participantes refletirem, produzirem, interpretarem, e distinguirem os contextos narrativos e narrados (Benveniste, 1971; Hanks, 1990; Jakobson, 1957; Silverstein, 1976; Wortham, 1996). Os participantes usam os deíticos para indicar uns aos outros o "aqui e agora" da interação imediata em relação ao "ali e nesse momento" do evento narrado. Para precisar, em relação aos materiais analisados neste artigo, os deíticos no Facebook dirigem e convidam os participantes a reconhecer o origo a partir do qual fazem a publicação e as entidades sobre os quais fazem a publicação.

Os participantes usam os deíticos para assinalar os posicionamentos intersubjetivos em relação ao contexto narrativo da diáspora em França e ao contexto narrado, como (imagens da) pátria portuguesa. No nosso caso, as publicações do Facebook usam deíticos para pôr em relação as interações de narrativas no ciberespaço de língua francesa, com viagens narradas para a pátria portuguesa, de modo que esses dois espaços-tempo pareçam mais ou menos contínuos ou simultâneos (Eisenlohr, 2004; Koven, 2007; Perrino, 2007; Silverstein, 1993; Wortham, 2001).

\section{Narração do nacionalismo}

Podemos perguntar-nos como integrar a atenção às práticas narrativas, entendidas no nível mais microsocial, em examinar como a narrativa pode contribuir para algo tão amplo quanto a diáspora e o nacionalismo. Como a discussão da deixis pode estar ligada ao nacionalismo diaspórico? De facto, para além da escala interpessoal, também extraímos perspetivas da antropologia linguística sobre a representação de identidades coletivas, especificamente identidades etno-nacionais. Embora essa outra literatura nem sempre tenha sido 
enquadrada em termos explicitamente narrativos, tem examinado como os atores sociais usam recursos deíticos, como a primeira pessoa do plural para refletir e produzir um sentido de identificações coletivas mais duradouras, como a do nacionalismo. Vários autores têm discutido como o uso do "nós" e das formas plurais deíticas associadas à primeira pessoa podem fornecer recursos-chave que refletem, criam, mobilizam e fazem circular identificações nacionais em contextos mundanos e cerimoniais (Derrida, 1986; Billig, 1995; Lee, 1995, Silverstein, 2000, Urban, 2000; Dori-Hacohen, 2014, Gal \& Woolard, 2001). Por exemplo, muito tem sido escrito sobre o "We" (nós) em "We the people..." da Declaração de Independência dos EUA. Esse "nós" assume e estabelece a própria coletividade a que se refere. No entanto, uma expressão escrita única de "nós, o povo" não foi suficiente para estabelecer a coletividade nacional de uma vez por todas (Lee, 1995; Silverstein, 2000, 2003; Urban, 2000). Nesse sentido, os autores têm defendido uma maior atenção para as práticas comunicativas recorrentes, através das quais os atores sociais imaginam, experimentam, promulgam e contextualizam o "nós" da comunidade nacional (Anderson, 1991).

Além disso, também se tem defendido uma perspetiva narrativa para reinterpretar a famosa discussão de Benedict Anderson sobre o nacionalismo como "comunidade imaginada". Para relembrar brevemente o argumento de Anderson, as nações são tipos estranhos de comunidades entre grandes grupos de pessoas, a maioria dos quais nunca se irão conhecer, mas que mesmo assim experimentam uns com os outros a partilha de uma posição coletiva, social, espacial e temporal. "De facto, um americano nunca irá conhecer pessoalmente ou mesmo conhecer os nomes dos mais de 240.000.000 americanos, nem tem ideia do seu quotidiano mas tem total confiança na sua atividade constante, anônima e simultânea." (Anderson, 1991: 26, traduzido por nós)

Como os antropólogos linguísticos têm notado, o que chamou a atenção no trabalho de Anderson foi o seu cuidado no papel das práticas comunicativas na construção e imaginação da comunidade, mais especificamente nas práticas de leitura partilhadas. Para a perspetiva histórica de Anderson, quando um grande número de pessoas desconhecidas consome produtos recentemente e amplamente disponíveis do capitalismo impresso, especialmente livros e jornais, esse conjunto de locutores pode vivenciar uma sensação de posicionamento partilhado e simultâneo de identidade no espaço e no tempo. Essa simultaneidade surge tanto em relação aos outros quanto em relação a um texto narrado particular, como a primeira página de um jornal diário. Essas práticas simultâneas de leitura e, mais especificamente, o facto de os participantes lerem os mesmos textos simultaneamente funciona para produzir um "nós" nacional narrativo. Ou seja, os membros de uma população formam-se numa narrativa coletiva e imaginam que partilham o mesmo espaço social e temporal em relação aos outros e em relação às figuras narradas nos textos impressos. Silverstein (2000) também usou essa perspetiva para reanalisar a discussão de Anderson (1991) sobre comunidades nacionalmente imaginadas, construídas em torno da leitura simultânea dos mesmos jornais e livros. "O nacionalismo é um sentido imaginativo da "expressão" bakhtiniana que enquadra pragmaticamente tudo o que é narrado na pressuposição de unidade de perspetiva num envelope comum, essencialmente assinalado no espaço e no tempo, de posicionamentos mútuos habitáveis." (Silverstein, 2000: 115, traduzido por nós). No entanto, Silverstein criticou a suposição de Anderson de que os projetos nacionalistas poderiam ser entendidos como faits accomplis, uma vez que os atores sociais devem empenhar-se continuamente em práticas comunicativas que renovam o sentido de um "nós" etno-nacional, pertencente a uma coletividade nacional imaginada (Silverstein, 2000, 2003).

\subsection{Narração do "nós" etno-nacional no Facebook}

Os media sociais permitem que os participantes produzam interativamente uma narrativa digital, através da qual constroem um conjunto de imagens narradas e desterritorializadas particulares da sua terra natal, com outros participantes que estão geograficamente dispersos (Appadurai, 1996; Axel, 2004; Eisenlohr, 2004; Bernal, 2005, 2006; Dick, 2010). 
Para recapitular, estendemos uma visão da prática social de práticas narrativas com múltiplos narradores e combinamos com uma visão linguística antropológica de comunidades imaginadas, para analisar as práticas comunicativas online reais através das quais os participantes do Facebook produzem um tipo particular de "nós" diaspórico. Esta perspetiva combinada ajudará a iluminar, sob o aspeto interacional e etnográfico, o que está em jogo no grupo particular do Facebook na diáspora, onde os participantes costumam dizer: "Vamos para a nossa pátria portuguesa".

Apresentaremos muito brevemente o contexto da diáspora portuguesa em França, juntamente com a do grupo analisado no Facebook. Em seguida, analisaremos as co-narrativas dos participantes do Facebook sobre viagens de férias para Portugal. Especificamente, mostraremos como os participantes usam um conjunto recorrente de estratégias para convidar os outros a apresentar e interpretar as viagens de férias para Portugal como uma experiência coletiva e até simultânea da diáspora portuguesa em França. Essas práticas produzem dois tipos interconectados de simultaneidade: o de estar junto como uma coletividade online e o de estar em dois lugares em simultâneo (online e na estrada).

Concluiremos refletindo sobre o que esses materiais revelam sobre a narrativa e, mais especificamente, sobre as narrações digitais de identidades coletivas.

\section{Diáspora portuguesa em França, offline e online}

Os participantes no grupo em estudo são, na sua maioria, descendentes da maior vaga de emigração portuguesa para França, ocorrida nas décadas de 1960 e 1970. Existem estimativas de mais de um milhão de portugueses a viver em França, e ainda mais se contarmos com as pessoas que se identificam como descendentes de portugueses, independentemente da nacionalidade. Os portugueses em França estão envolvidos numa série de práticas móveis transnacionais (Basch et al., 1994; Appadurai, 1996; Koven, 2004; Tsuda, 2009; Dos Santos, 2010; Pereira, 2016). Uma dessas práticas recorrentes é a viagem entre França e Portugal. Em particular, as férias de verão de França para Portugal são um hábito estabelecido entre famílias de descendência portuguesa em França (De Villanova, 1988; Charbit, Hily \& Poinard, 1997; Dos Santos, 2010; Wagner, 2011). Estas viagens de verão são uma das formas com que os descendentes de emigrantes portugueses têm cultivado ligações com Portugal, constituindo um tipo de turismo diaspórico ou turismo de raízes (Basu, 2007; Wagner, 2011).

Dito isto, não são apenas as viagens reais de verão para Portugal que são transnacionais, como também o facto de os participantes conversarem com outras pessoas sobre essas mesmas viagens. Antes do aparecimento dos media sociais, os participantes já narravam essas viagens oralmente em interações face-aface com amigos e familiares (Koven, 2007, 2013). No entanto, com o surgimento e a disseminação dos media sociais, os participantes podem agora partilhar os seus regressos a Portugal com milhares de outras pessoas online. O ciberespaço oferece aos participantes um novo tipo de presença simultânea ou de comunidade com desconhecidos. Podem partilhar online a experiência de residir no norte da Europa francófona, enquanto simultaneamente anseiam e viajam para Portugal (ver também Koven \& Simões Marques, 2015). Veremos como ligam as suas viagens reais com os seus discursos sobre essas mesmas viagens.

\section{Grupo Diaspórico no Facebook: Tu sais que tu viens du Portugal Quand...}

Realizámos uma análise detalhada das interações no grupo Tu sais que tu viens du Portugal Quand.../“Sabes que és de origem portuguesa quando...”. O grupo é composto por aproximadamente 40000 membros, em grande parte descendentes de emigrantes portugueses em França (como também na Suíça e na Bélgica), que se reúnem através de interesses partilhados (Fono \& Raynes-Goldie, 2006; Rosen, 2007). Neste 
caso, o interesse comum é a origem e a identidade portuguesas para os que vivem em países de língua francesa, conforme indicado através do próprio nome do grupo. Através da sua formulação em francês, a menção de origem portuguesa e o uso de formas pronominais e verbais da segunda pessoa, o nome do grupo aborda e convida um destinatário genérico da diáspora a partilhar posts textuais e visuais que convidam o reconhecimento de si e dos outros como sendo portugueses (pelo menos por descendência) e francófonos. Este grupo permite que migrantes portugueses "de segunda e terceira geração", dispersos geograficamente, se conectem uns com os outros, em torno de uma combinação de construções partilhadas de Portugal como pátria e o uso da língua francesa.

\subsection{Publicações de viagens de férias para Portugal}

O grupo consiste basicamente no facto de os locutores partilharem o que De Fina \& Georgakapoulou chamam de "pequenas histórias" (small stories) (Georgakapoulou, 2007; De Fina, 2016), ou seja, breves mensagens episódicas e plurilingues com a presença de textos, imagens ou vídeos, muitas vezes seguidas por likes e/ou comentários de outros membros. Os posts incluem textos escritos e imagens visuais da cultura popular ou folclórica francesa e portuguesa, como o futebol, a música, a comida ou até a política.

Mais particularmente, a partilha das viagens e férias em Portugal é um tipo de post extremamente frequente e apreciado. Estendendo-se de junho de 2014 a abril de 2015, analisámos um conjunto de posts de partilha de férias, incluindo 247 posts originais, 1530 comentários e 25602 likes. Estes lugares dizem respeito às várias fases da viagem: a partida antecipada de França, a viagem de carro, o atravessar da fronteira, as atividades realizadas em Portugal e a viagem de regresso a França.

Os participantes evocam essas viagens uns para os outros, assumindo perspetivas partilhadas como membros de pensamento semelhante da diáspora portuguesa em países de língua francesa. Ou seja, postam e comentam essas viagens a partir de um origo narrativo compartilhado da diáspora francófona sobre o evento narrado da própria viagem, que todos partilham. Assim, podemos examinar com precisão como os participantes comunicam entre si no espaço-tempo do Facebook, sobre o espaço-tempo narrado da estrada para a pátria portuguesa. Então, além de realizarem a identidade portuguesa através de viagens de regresso reais, realizam-na também através das narrações dessas viagens neste contexto online, laminando o reino narrado da estrada, e o reino narrativo de suas interações online. Discutiremos as estratégias recorrentes que os participantes usam para convidar os membros do grupo no Facebook para acompanhá-los virtualmente nas suas viagens reais a Portugal. Essas estratégias envolvem a vinculação de perspetivas individuais e coletivas e a criação de uma simultaneidade de eventos narrativos e narrados.

\section{Criando comunidade e simultaneidade}

Os participantes usam estratégias deíticas que ligam as viagens únicas dos posts individuais a imagens dessas mesmas viagens de férias como coletivas e típicas para todos aqueles do grupo e para a diáspora portuguesa em geral. Vemos isso no Exemplo (1) (ver supra), onde o participante usa on/nós, o presente do indicativo, o verbo direcional arriver/“chegar" (implicitamente da diáspora para a pátria portuguesa), e a imagem postada da perspetiva dos passageiros dentro do veículo que olham em direção à estrada. Mais uma vez, esses posts não se limitam a relatar a experiência individual, mas convidam outros a promulgar, de forma colaborativa, uma orientação partilhada em relação ao significado geral da viagem a Portugal para aqueles que estão em França.

Assim, podemos dizer que os participantes usam recorrentemente as seguintes estratégias para convidar os outros a reconhecerem-se e a integrarem-se na comunidade diaspórica, através dos contextos narrados e de narração: 
- uso ou alternância de formas que apresentam atores coletivos e genéricos, tais como "nós"/ "nossos" ou formas verbais associadas (Benveniste, 1971; Pavlidou, 2014) ou ainda a forma genérica "tu/teu" (O'Connor, 1994; Myers \& Lamproproulou, 2012; Stirling \& Manderson, 2011);

- verbos no presente do indicativo, que apresentam experiências e ações típicas ou simultâneas ligadas com o evento da narração:

- uso de um presente atemporal (Silverstein, 1993; Agha, 2006; Koven, 2016) (para destacar a tipicidade) - fazendo parecer que o evento narrado esteja a desdobrar-se em tempo real, semelhante ao presente histórico (Wolfson, 1979; Schiffrin, 1981; Georgakapoulou, 2007; Perrino, 2007);

- verbos direcionais e expressões adverbiais, tais como retour/"regresso", aller/ "ir", maison/ "lar/casa", que indicam o movimento da França para Portugal e novamente para França (Haviland, 2005);

- imagens visuais e/ou vídeos transmitidos a partir de pontos de vista específicos (por exemplo, do condutor ou do passageiro dentro de um automóvel, em direção à estrada).

Ao usar estas estratégias, os membros incentivam-se mutuamente a viver num espaço-tempo de narração em relação a um espaço-tempo narrado da viagem para e desde Portugal. Iremos apresentar exemplos que ilustram estas tendências.

\subsection{Antecipar a partida}

Vemos uma combinação das estratégias listadas acima no Exemplo (2) em posts que anunciam uma partida iminente, próxima futura, ou simultânea para Portugal. As formas visuais e verbais servem para convidar outros membros a reconhecer coletivamente e inserir-se virtualmente num espaço-tempo partilhado da viagem diaspórica.

(2) Quand tu sais qu'à la fin du mois tu prendra la route vers notre beau pays avec uma boa ranchada nas orelhas.

(pt.) Quando sabes que no final do mês vais apanhar a estrada para o nosso belo país com uma boa ranchada nas orelhas.

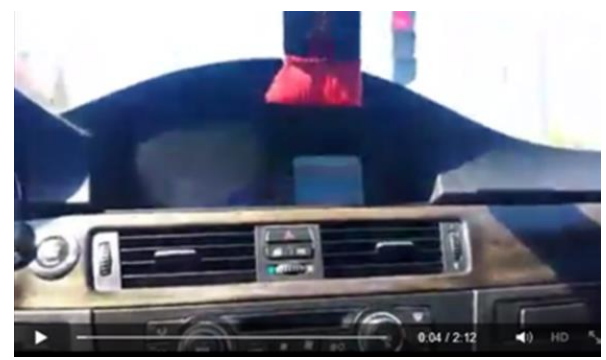

Figura 2

A imagem visual, extraída de um vídeo, mostra a perspetiva incorporada de um passageiro olhando para a estrada. A imagem coocorre com as formas verbais que reforçam o convite a outros membros do grupo para partilhar e inserir-se nas perspetivas narrativa e narradas: segunda pessoa generalizada ( $t u$ ), primeira pessoa do plural (notrel "nosso") e expressões de movimento direcional (prendre la route vers/"apanhar a estrada em direção a"). Neste caso, a primeira pessoa do plural notre/"nosso" parece referir-se ao participante e a outros, implicitamente incluindo os membros do grupo do Facebook com todos os portugueses diaspóricos. Essas estratégias visuais e verbais funcionam para apresentar a viagem como um evento típico. De facto, na medida 
em que likes e comentários são uma indicação da eficácia geral de um post, podemos notar que este obteve 200 likes e 90 comentários. Argumentamos que tais posts são eficazes pois permitem ao grupo partilhar virtualmente a experiência emblemática da viagem para Portugal. De facto, podemos ver como os comentários respondem ao convite coletivo do post, muitas vezes ao adotar também formas coletivas genéricas semelhantes. No Exemplo (3), vemos um comentário que também trata a viagem como uma experiência coletiva, apreendida a partir de uma perspetiva partilhada sobre a identidade etno-nacional e diaspórica portuguesa.

(3) Boa viagem Il n'y a que les portugais qui peuvent savoir \& ressentir l'attachement et l'alegria de regressar ao nosso pais

(pt.) Boa Viagem $\underline{\text { Só os portugueses podem saber e sentir o apego e a alegria de regressar ao nosso }}$ país

Note como o comentário aborda diretamente outros membros do grupo (Boa Viagem), seguido de uma referência explícita à particularidade da identidade portuguesa (Il n'y a que les portugais/ "Só os portugueses"), emblematicamente expresso em língua portuguesa e o uso da primeira pessoa do plural possessivo nosso. Esse conjunto de formas liga e confunde os participantes na interação atual no Facebook com todos os Portugueses na diáspora.

Quando os comentadores escrevem como indivíduos que narram as suas próprias viagens individuais mesmo assim podem ligar formas da primeira pessoa do singular à primeira pessoa do plural.

Nos exemplos (4), (5) e (6), vemos que os comentadores individuais conectam experiências individuais de afeto (antecipação ansiosa) e nostalgia à nossa terra, ligando assim uma experiência individual ao coletivo.

(4) K... passe le bonjour à nossa terra de Ponte de Lima, dis lui que je serai bientôt la se deus quiser (pt.) K ... manda cumprimentos à nossa terra de Ponte de Lima, diz-lhe que em breve estarei aí se Deus quiser

(5) trop hate d'etre retour a la maison (nosso minho)

(pt.) estou mesmo ansioso por voltar à casa (nosso Minho)

(6) Saudades .... Hâte d'y retourner très prochainement!!

PortugalNoCoraçaoNazaré

(pt.) Saudades... Anseio por voltar muito em breve!!

\# PortugalNoCoraçaoNazaré

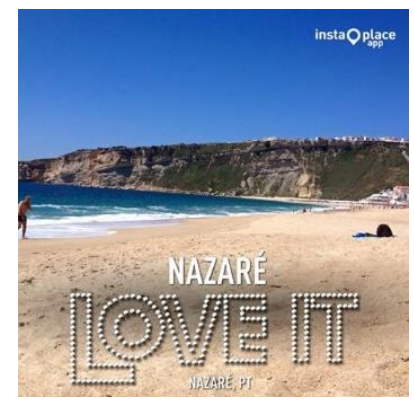

Figura 3

Cada post inclui uma forma singular da primeira pessoa (je serai/“estarei”, trop hâte/"mesmo ansioso") frequentemente seguida por formas plurais, como em nossa terra. Cada exemplo também contém expressões de movimento direcional que posicionam o participante como escrevendo de fora mas dirigindo-se para 
Portugal, mencionando frequentemente regiões ou cidades específicas de Portugal ao apresentar Portugal como um lar e uma fonte autênticos para os quais todos procurar retornar.

Os membros individuais, que ainda não estão realmente na estrada no mesmo momento em que o post é escrito, podem participar virtualmente, exibindo o reconhecimento da viagem evocada como emblemática deste tipo de evento. De facto, muitos relatam datas específicas para as suas viagens individuais futuras. Acompanhados por interjeições em língua portuguesa, esses posts exibem uma emoção antecipatória carregada de forma afetiva.

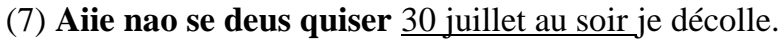

(pt.) oh não, se Deus quiser dia 30 de julho à noite vou embora

(8) Vivement le 2 Août que je trace direction Ponte de Lima caralho !!!

(pt.) Mal posso esperar, no dia 02 de agosto vou direção Ponte de Lima caralho!!!

Nos Exemplos (7) e (8), o autor usa um verbo na primeira pessoa do singular do presente do indicativo para uma viagem no futuro próximo (je décolle/"vou embora", je trace/"vou"), com expressões de movimento direcional de um origo implícito de França para o destino português.

De salientar que mesmo aqueles que não podem viajar podem ainda ligar-se à experiência coletiva e virtual, partilhando os anseios de viajar para Portugal. Fazem-no apresentando viagens (realizadas ou não) como experiências não só específicas/individuais como também gerais/coletivas.

(9) Aouf !! Les frissons ... c'est trop bon ça mais malheureusement je pars pas cette année! Bonnes vacances à ts ceux et celles qui partent, amusez vs bien et bonne route, biz.

(pt.) Ai! Calafrios ... isso é tão bom, mas infelizmente não viajo este ano! Desejo umas boas férias a todos que estão indo, divirtam-se e façam boa viagem, beijos

No Exemplo (9), o participante primeiro responde à viagem de um post anterior com interjeições afetivas e uma avaliação positiva (Aouf !! Les frissons... c'est trop bon çal“Ai!! Calafrios... isso é tão bom”), seguido imediatamente por uma indicação de que não viajará este ano (je pars pas/"não vou”). Com o uso de cette année/"este ano" o locutor lamenta o facto de não viajar e dirige-se a todos aqueles que viajarão. Por meio dessas combinações e alternâncias de posicionamento ou de footing (Goffman, 1979), o comentador apresenta viagens específicas e considera a viagem como desejada e altamente afetiva. Quer um comentador realmente viaje ou não, vemos que pode sinalizar o reconhecimento em relação a viagens para Portugal como componentes centrais e emocionalmente carregados da experiência diaspórica do ser português. Além disso, aqueles que viajam podem demonstrar compaixão por aqueles que não o podem fazer.

(10) Ça y est. Avec qq heures de retard, l'heure H est arrivée. Manque plus que le chauffeur, moi hihi, et c'est parti pour une quinzaine voire vingtaine d'heures de vroum ! Grosse pensée à ceux et celles qui n'auront pas la possibilité d'aller embrasser notre terre! Viva Portugal!!!!!

(pt.) Já está. Com algumas horas de atraso, a hora H chegou. Só falta o condutor, eu hihi, e vamos nós por cerca de quinze ou até vinte horas de vroum! $\underline{\mathrm{O} \text { meu pensamento está com aqueles que não terão a }}$ oportunidade de vir beijar a nossa terra! Viva Portugal !!!!! 


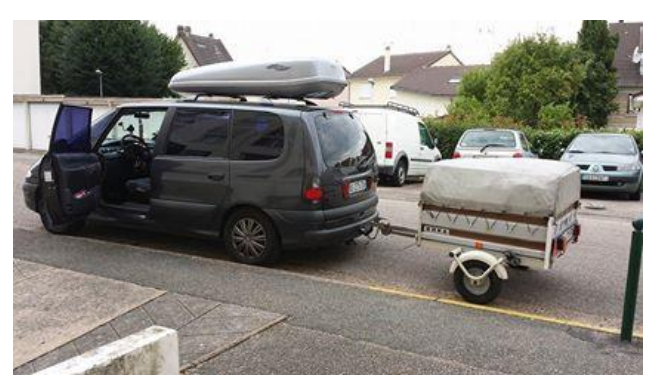

Figura 4

Este post do Exemplo (10) e da Figura 4 inicia o comentário contando uma viagem individual iminente. O post aborda diretamente qualquer não-viajante, mostrando compaixão por perder esta "oportunidade". Note-se novamente o verbo direcional allerl "ir" e a forma possessiva na primeira pessoa do plural (notre terrel "nossa terra".

\subsection{Simultaneidade}

Estas práticas também permitem que os participantes partilhem experiências como se estivessem ocorrendo no presente. Embora os participantes geralmente não transmitem as suas imagens ao vivo, as imagens e as estratégias deíticas aparecem como se o autor da publicação o dissesse em tempo real:

(11) C'eeeest parti pour le Portugaaaaal caralho Sur tout le chemin avec des musiques comme ça (pt.) Vaaaaamos embora para Portugaaaaal caralho Ao longo do caminho com músicas como esta

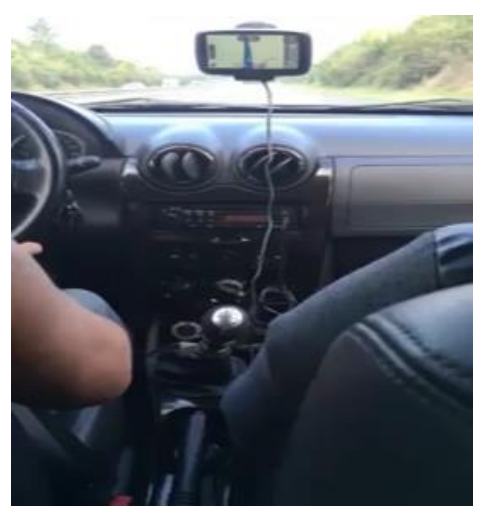

Figura 5

O autor, na figura 5, estabelece um sentido de experiência imediata e simultânea da estrada com os outros membros do grupo através do uso combinado do presente, das vogais ortograficamente repetidas e da expressão deítica comme ça/“como esta”, referindo-se à música no vídeo que o acompanha. Esta publicação foi muito apreciada, suscitando 619 apreciações e 202 comentários.

Através de estratégias que combinam eventos narrados e narrativos, os autores das publicações convidam os outros a "juntarem-se" à sua viagem. Vemos uma criação semelhante em tempo real, de coletividade e de simultaneidade nas seguintes publicações: 
(12) Portugal Vamos Nos, Bonne Vacances à Tous!

(pt.) Portugal Vamos Nós, Boas Férias a Todos!

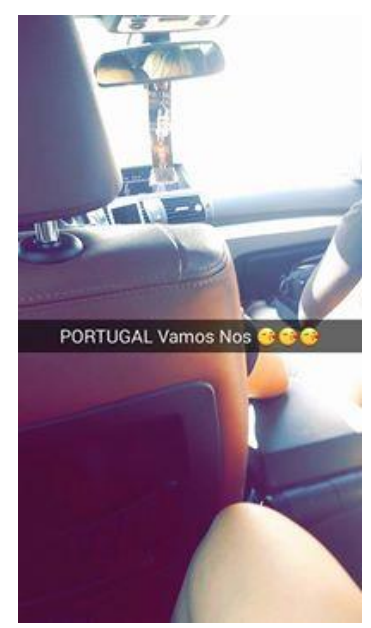

Figura 6

(13) Enfin on passe la frontière après $17 \mathrm{~h}$ de route et tout sa avec le soleil Oklm\#Portugal

(pt.) Finalmente, cruzamos a fronteira depois de $17 \mathrm{~h}$ de estrada e tudo isto com sol tranquilo\# Portugal

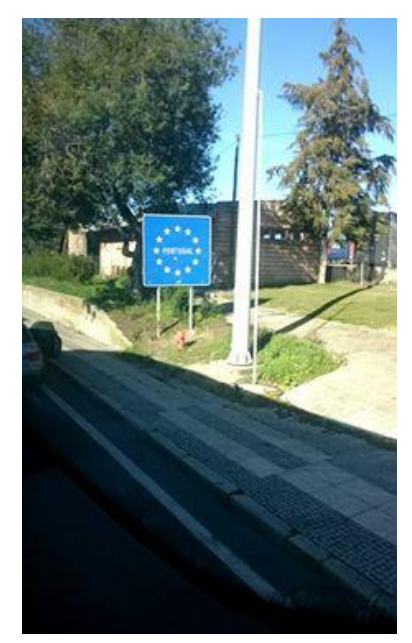

Figura 7

O presente do indicativo reflete um sentimento de convergência entre a publicação e a viagem. O on/"nós" e o nous/ "nós" mostram uma certa flexibilidade estratégica (Pavlidou, 2014), referindo-se potencialmente não só ao autor da publicação, além dos passageiros no seu carro, como também a todos os portugueses no exterior que vão para Portugal. Como nos exemplos anteriores, as formas visuais e verbais criam e fundem uma impressão de coletividade e simultaneidade de perspetiva para todos os potenciais 
viajantes. Desta forma, em vez de contar a viagem individual de um único autor, estas formas e imagens verbais apresentam e apelam a narração de experiências comumente reconhecidas.

\subsection{Narrando um regresso comum para França}

Muitas dessas estratégias também aparecem em posts sobre a viagem de regresso a França. Os participantes narram esses eventos com formas pronominais genéricas e/ou coletivas e tempos verbais que mostram um reconhecimento partilhado, em relação a outros membros do grupo e às imagens mostradas. No entanto, os origines visuais e deíticos, as "chaves" afetivas (ver Hymes, 1972) e as expressões direcionais são um pouco diferentes daqueles que vão a caminho de Portugal. Em vez de imagens da estrada, as mensagens sobre a viagem de regresso a França normalmente apresentam imagens tiradas do lado de fora de um veículo sobrecarregado, antes mesmo do início da viagem, conforme Figura 8. Ao contrário das imagens em direção a Portugal, o que se destaca não é a viagem em si, mas sim os desafios de transportar literalmente um pouco de Portugal para a França. Enquanto o afeto em torno da viagem para Portugal é de alegria e antecipação, a viagem de regresso evoca a tristeza.

(14) Tu quite ton village. ....mdr et les larmes aux yeux

(pt.) Deixas a tua aldeia. ... lol com lágrimas nos olhos

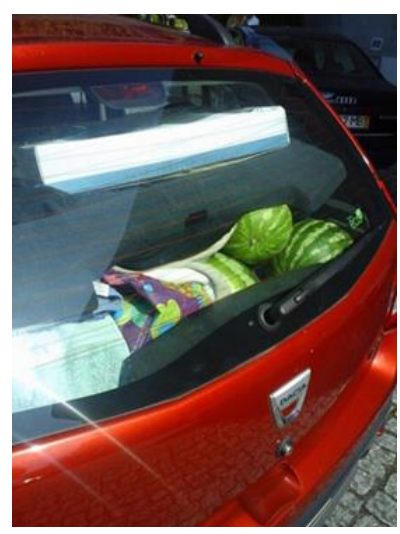

Figura 8

(15) C'est tellement ça ! Je pense qu'on ressent tous la même chose a ce moment là.. On se dit qu'on a attendu 1 an pour vivre de superbes vacances dans notre si beau pays et à peine arrivée il est déjà temps de repartir et à présent il nous reste plus qu'à attendre le retour avec impatience ...

(pt.) É isso mesmo Acho que todos nós sentimos a mesma coisa naquele momento... Esperámos um ano para ter uma ótimas férias no nosso belo país e mal chegamos já é hora de partir e agora apenas temos que esperar pelo regresso com impaciência...

Com o uso de sujeitos genéricos ou coletivos (on-nous/“nós", notre/ "nosso", tu), estes posts destacam e chamam os outros a participarem das experiências narradas e das narrativas simultâneas e compartilhadas de todos os portugueses da diáspora que no final do verão têm de regressar a França. 


\section{Conclusão}

Discutimos a maneira como os portugueses diaspóricos francófonos recorrem à rede social Facebook para contar aos outros membros as suas viagens a Portugal, como experiência coletiva e potencialmente simultânea do grupo do Facebook e dos portugueses da diáspora em geral. Participam ainda dessas interações narrativas com outros que também residem no exterior e que podem continuar a postar no grupo enquanto ainda estão em França e/ou enquanto estão de férias em Portugal. Ao combinar formas verbais e visuais que convidam os outros a reconhecer e juntar-se a essas viagens de regresso como um tipo de evento, os participantes criam a sensação de estarem juntos, tanto online como na estrada, dando a impressão de uma coletividade ou de uma simultaneidade do ser português diaspórico. São férias virtuais partilhadas que os participantes contam num espaço-tempo francófono sobre um espaço-tempo português narrado. Estas práticas envolvem dois tipos de simultaneidade interconectada: estar junto como um grupo diaspórico online, e estar simultaneamente online e na estrada, envolvendo momentos de unidade interacional. Mostrámos as estratégias usadas pelos atores sociais para produzirem e imaginarem coletividades na escala das comunidades nacionais e diaspóricas. Ambas se aglutinam-se, produzindo discursivamente momentos de união interacional e de simultaneidade.

Esta experiência discursiva de simultaneidade interacional assemelha-se a e entrelaça-se com viagens reais através de formas complexas. As narrativas de viagens a Portugal no Facebook não são, portanto, facilmente separáveis das viagens "reais". As narrativas aqui analisadas fornecem um meio discursivo através do qual os participantes partilham em conjunto versões específicas da identidade diaspórica, pois publicam a partir de um espaço-tempo aqui em França, ansiando por uma comunhão lá em Portugal, enquanto estão juntos em ambos os lugares.

Devemos também salientar o que estas práticas de comunicação revelam sobre a narração e como a análise narrativa contribui para a compreensão dessas práticas. Esses atores sociais usam estratégias narrativas não-canónicas, pois convidam outros membros do grupo a partilharem de forma coletiva múltiplos espaços e tempos. Por meio desses convites, os participantes solicitam que desconhecidos reconheçam, enfatizem e produzam dimensões coletivas da vida social e afetiva. Ao abraçar a noção de narrativas como prática social, a pesquisa sobre narrativa deve considerar mais amplamente como os narradores podem falar além de suas capacidades como indivíduos únicos (Goffman, 1979/1981). Embora os estudos tenham discutido os modos heteroglóssicos de contar narrações vinculados a contextos sociais "macro" mais amplos (De Fina, 2012; Hill, 1995), concentrando-se em locutores individuais ou estruturas de participantes face a face relativamente pequenas, um certo individualismo e um foco micro-analítico muitas vezes têm permanecido na pesquisa narrativa. A ideia permanece que os indivíduos possuem as experiências que narram, como se fossem um conteúdo interior (Bauman and Briggs 2003), em vez de construções colaborativas. Em vez de privilegiar o relato individual de experiências passadas, mostrámos como os participantes podem usar as práticas narrativas como convites que fazem para os outros construírem espaços e tempos das experiências compartilhadas. Considerámos também numa escala maior, agentes coletivos e projetos para os quais a prática da narração social pode contribuir.

Dito isto, além da literatura estritamente narrativa, também mostrámos as estratégias narrativas em interações mundanas e online, através das quais os atores sociais produzem e imaginam coletividades de maior escala de nacionalismo e diáspora. Os participantes do Facebook usam formas narrativas multimodais que combinam e vinculam o indivíduo ao coletivo, perspetivas específicas às perspetivas genéricas e online. Ao fazê-lo, os participantes poderiam convidar os outros a reconhecer, habitar e fazer circular formas particulares de identificação partilhada. Essas práticas criam um novo contexto onde as práticas comunicativas podem ser usadas para realizar as comunidades imaginadas. 


\section{Referências}

Agha, A. (2005) Voicing, footing, enregisterment. Journal of Linguistic Anthropology 15 (1), pp. 38-59.

Agha, A. (2006) Language and social relations. New York: Cambridge University Press.

Anderson, B. (1991) Imagined communities: Reflections on the origin and spread of nationalism. Ithaca: Cornell University Press.

Appadurai, A. (1996) Modernity at large. Minneapolis: University of Minnesota Press.

Androutsopoulos, J. (2010) The study of language and space in media discourse. In P. Auer \& J. E. Schmidt (Eds.) Language and space: An International handbook of linguistic variation. Volume I: Theory and methods. Berlin/New York: de Gruyter, pp. 740-758.

Axel, B. (2004) The context of diaspora. Cultural Anthropology 19 (1), pp. 26-60.

Baquedano-López, P. (2000) Narrating community in doctrina classes. Narrative Inquiry 10 (2), 1-24.

Bakhtin, M. (1981) The dialogic imagination. Austin: University of Texas Press.

Bamberg, M. (1997) Positioning between structure and performance. Journal of Narrative and Life History 7 (1-4), pp. 335-342.

Basch, L., Glick-Schiller, N., \& Szanton-Blanc, C. (1994) Nations unbound. Transnational projects, postcolonial predicaments and deterritorialised nation-states. Amsterdam: Gordon \& Breach Science Publishers.

Basu, P. (2007) Highland homecomings: Genealogy and heritage tourism in the Scottish diaspora. New York: Routledge.

Bateman, A. (2014) Children's use of English 'we' in a primary school in Wales. In S. Pavlidou (Ed.) Constructing collectivity: 'We' across languages and contexts). Amsterdam: John Benjamins, pp. 227246.

Bauman, R. (1986) Story, performance, and event: Contextual studies of oral narrative. New York: Cambridge University Press.

Bauman, R., \& Briggs, C. (2003) Voices of modernity. New York: Cambridge University Press.

Bazzanella, C. (2014) Grammar, interaction, and context: Unmarked and marked uses of the first-person plural in Italian. In S. Pavlidou (Ed.) Constructing collectivity: 'We' across languages and contexts, Amsterdam: John Benjamins, pp. 83-104.

Benveniste, E. (1971) Problems in general linguistics. Miami: University of Miami Press.

Bernal, V. (2005) Eritrea on-line: Diaspora, cyberspace, and the public sphere. American Ethnologist 32 (4), pp. 660-675.

Bernal, V. (2006) Diaspora, cyberspace, and political imagination: The Eritrean diaspora online. Global Networks 6 (2), pp. 161-179.

Billig, M. (1995) Banal nationalism. London: Sage.

Brettell, C. (2003) Anthropology and migration: Essays on transnationalism, ethnicity, and identity. Walnut Creek, California: Altamira.

Charbit, Y., Hily, M. A., \& Poinard, M. (1997) Le va-et-vient identitaire. Migrants Portugais et villages d'origine. Paris: Persée.

De Fina, A. (2003) Identity in narrative: A study of immigrant discourse. Amsterdam: John Benjamins.

De Fina, A. (2012) Analyzing narrative: Discourse and sociolinguistic perspectives. New York: Cambridge University Press.

De Fina, A. (2016) Storytelling and audience reactions in social media. Language in Society 45, pp. 473-498.

De Fina, A., \& Georgakapoulou, A. (2015) Handbook of narrative analysis. Malden, MA: Wiley Blackwell.

Derrida, J. (1986) Declarations of Independence. New Political Science 15, pp. 7-15. 
De Villanova, R. (1988) Le portugais : une langue qui se ressource en circulant. In G. Vermès (Ed.) Vingtcinq communautés linguistiques de la France. Paris: L'Harmattan, pp. 283-300.

Dick, H. (2010) Imagined lives and modernist chronotopes in Mexican nonmigrant discourse. American Ethnologist 37 (2), pp. 275-290.

Dori-Hacohen, G. (2014) Establishing social groups in Hebrew: 'We' in political radio phone-in programs. In S. Pavlidou (Ed.) Constructing collectivity: 'We' across languages and contexts. Amsterdam: John Benjamins, pp. 187-206.

Dos Santos, I. (2010) Les brumes de la mémoire. Expérience migratoire et quête identitaire de descendants de Portugais de France (Doctoral thesis). Paris : École des Hautes Études en Sciences Sociales.

Duranti, A. (1986) The audience as co-author: An introduction. Text 6 (3), pp. 239-247.

Eisenlohr, P. (2004) Temporalities of community: Ancestral language, pilgrimage, and diasporic belonging in Mauritius. Journal of Linguistic Anthropology 14 (1), pp. 81-98.

Fono, D., \& Raynes-Goldie, K. (2006) Hyperfriends and beyond: Friends and social norms on LiveJournal. In M. Consalvo \& C. Haythornthwaite (Eds.) Internet research annual Volume 4: Selected papers from the Association of Internet Researchers Conference. New York: Peter Lang, pp. 91-103.

Gal, S., \& Woolard, K. (2001) Languages and publics. Manchester: St. Jerome's.

Georgakapoulou, A. (2007) Small stories, interaction, and identities. Amsterdam: John Benjamins.

Georgakapoulou, A. (2015) Introduction: Communicating time and place on digital media-multi-layered temporalities and (re)localizations. Discourse, Context, and Media 9, pp. 1-4.

Goffman, E. (1981) [1979] Footing. In E. Goffman, Forms of talk. Philadelphia: University of Pennsylvania Press, pp. 124-159.

Gonçalves, A. (1996) Imagens e Clivagens: Os residentes face aos emigrantes. Porto: Edições Afrontamento.

Goodwin, M. H. (1990) He-said-she-said: Talk as social organization among Black children. Bloomington: Indiana University Press.

Goodwin, M. H. (1997) Toward families of stories in context. Journal of Narrative and Life History 7 (1-4), pp. $107-112$.

Hanks, W. (1990) Referential practice: Language and lived space among the Maya. Chicago: University of Chicago Press.

Haviland, J. (2005) Dreams of blood: Zincantecs in Oregon. In M. Baynham \& A. De Fina (Eds.) Dislocations/relocations. Manchester, UK: Saint Jerome's, pp. 91-127

Helmbrecht, J. (2002) Grammar and function of 'we.' In A. Dusckak (Ed.) Us and others: Social identities across languages. Amsterdam: John Benjamins, pp. 31-49.

Heyd, T., \& Honkanen, M. (2015) From Naija to Chitown: The new African diaspora and digital representations of place. Discourse, Context, and Media 9, pp. 14-23.

Hill, J. (1995) The voices of Don Gabriel: Responsibility and self in a modern Mexicano narrative. In D. Tedlock \& B. Mannheim (Eds.) The dialogic emergence of culture. Urbana, IL: University of Illinois Press, pp. 97-147.

Hymes, D. H. (1972) On Communicative Competence. In Pride, J. B., \& Holmes, J. (Eds.) Sociolinguistics, Baltimore, USA: Penguin Education, Penguin Books Ltd, pp. 269-293.

Jakobson, R. (1957) Shifters, verbal categories, and the Russian verb. Cambridge: Harvard University.

Jenkins, H. (2006) Convergence culture. New York: New York University Press.

Koven, M. (2002) An analysis of speaker role inhabitance in narratives of personal experience. Journal of Pragmatics, 34 (2), pp. 167-217.

Koven, M. (2004) Transnational perspectives on sociolinguistic capital among Luso-descendants in France and Portugal. American Ethnologis, 31 (2), pp. 270-290.

Koven, M. (2007) Selves in two languages. Amsterdam: John Benjamins. 
Koven, M. (2013) Speaking French in Portugal: An analysis of contested models of emigrant personhood in narratives about return migration and language use. Journal of Sociolinguistics 17 (3), pp. 324-354.

Koven, M. (2016) Essentialization strategies in the storytellings of young Luso-descendant women in France: Narrative, calibration, voicing, and scale. Language and Communication 46, pp. 19-29.

Koven, M., \& Simões Marques, I. (2015) Performing and evaluating (non)modernities of Portuguese migrant figures on YouTube: The case of Antonio de Carglouch. Language in Society 44, pp. 213-242.

Labov, W. (1972) Language in the inner city. Philadelphia: University of Pennsylvania Press.

Leal, J. (2000) Etnografias Portuguesas (1870-1970). Cultura popular e Identidade Nacional. Lisboa: Dom Quixote.

Lee, B. (1995) Performing the people. Pragmatics 5 (2), pp. 263-280.

Lempert, M., \& Perrino, S. (2007) Entextualization and the ends of temporality. Language and Communication 27 (3), pp. 205-211.

Mandelbaum, J. (2013) Storytelling in conversation. In Sidnell, J. \& Stivers, T. (Eds.) Handbook of conversation analysis. Cambridge: Cambridge University Press, pp. 492-508.

Marques, I. Simões \& Koven, M. (2017) "We are going to our Portuguese homeland!" French Lusodescendants' diasporic Facebook conarrations of vacation return trips to Portugal, Narrative Inquiry 27, 2, pp. 286-310.

Muhlhauser, P., \& Harre, R. (1990) Pronouns and people: The linguistic construction of social and personal identity. Malden, MA: Blackwell.

Myers, G. \& Lampropoulou, S. (2012) Impersonal you and stance-taking in social research interviews. Journal of Pragmatics 44/10, pp. 1206-1218.

Ochs, E. (1994) Stories that etep into the future. In D. Biber \& E. Finnegan (Eds.) Sociolinguistic perspectives on register. Oxford: Oxford University Press, pp. 106-135.

Ochs, E., \& Capps, L. (2000) Living narrative. New York: Cambridge University Press.

O’Connor, P. (1994) "You could feel it through your skin": Agency and positioning in prisoners' stabbing stories. Text 14 (1), pp. 45-75.

Page, R. (2012) Stories and social media. New York: Routledge.

Pavlidou, T. S. (2014) Constructing collectivity: 'We' across languages and contexts. Amsterdam: John Benjamins.

Pereira, V. (2016) Portuguese migrants and Portugal: Elite discourses and transnational practices. In N. Green \& R. Waldinger (Eds.) A century of transnationalism: Immigrants and their homeland connections. Urbana: University of Illinois.

Perrino, S. (2007) Cross-chronotope alignment in Senegalese oral narrative. Language and Communication 27 (3), pp. 227-244.

Polanyi, L. (1979) So what's the point? Semiotica 25 (3-4).

Rosen, C. (2007) Virtual friendship and the new narcissism. The New Atlantis 17, pp. 15-31.

Schiffrin, D. (1981) Tense variation in narrative. Language 57 (1), pp. 45-62.

Silverstein, M. (1976) Shifters, linguistic categories, and cultural description. In K. Basso \& H. Selby (Eds.) Meaning in anthropology. Albuquerque, NM: University of New Mexico Press, pp. 11-55.

Silverstein, M. (1993) Metapragmatic discourse and function. In J. Lucy (Ed.) Reflexive language. New York: Cambridge University Press, pp. 33-57.

Silverstein, M. (2000) Whorfianism and the linguistic imagination of nationality. In P. Kroskrity (Ed.) Regimes of language. Santa Fe: School of American Research Press, pp. 85-138.

Silverstein, M. (2003) The whens and wheres - as well as hows - of ethnolinguistic recognition. Public Culture 15 (3), pp. 531-557.

Silverstein, M. (2005) Axes of evals. Journal of Linguistic Anthropology 15 (1), pp. 6-22. 
Stirling, L., \& Manderson, L. (2011) About you: Empathy, objectivity, and authority. Journal of Pragmatics 43/6, pp. 1581-1602.

Tsuda, T. (2009) Diasporic homecomings: Ethnic return migration in comparative perspective. Palo Alto: Stanford University Press.

Urban, G. (2000) Metaculture: How culture moves through the world. Minneapolis: University of Minnesota Press.

Van De Mieroop, D. (2014) On the use of 'we' in Flemish World War II interviews. In S. Pavlidou (Ed.) Constructing collectivity: 'We' across languages and contexts. Amsterdam: John Benjamins, pp. 309-330.

Van De Mieroop, D. (2015) Social identity theory and the discursive analysis of collective identities in narratives. In A. De Fina \& A. Georgakapoulou (Eds.) Handbook of narrative analysis. Malden, MA: Wiley Blackwell, pp. 408-428.

Wagner, L. B. (2011) Negotiating diasporic mobilities and becomings: interactions and practices of Europeans of Moroccan descent on holiday in Morocco (Doctoral thesis). London: University College London.

Whitt, R. J. (2014) Singular perception, multiple perspectives through 'we': Constructing intersubjective meaning in English and German. In S. Pavlidou (Ed.) Constructing collectivity: 'We' across languages and contexts. Amsterdam: John Benjamins, pp. 45-64.

Wolfson, N. (1979) The conversational historical present alternation. Language, 55/1, pp. 168-182.

Wortham, S. (1996) Mapping participant deictics: A technique for discovering speakers' footing. Journal of Pragmatics, 25 (3), pp. 331-348.

Wortham, S. (2001) Narratives in action. New York: Teachers' College Press. 